\title{
Ability of the Mandarina Bavaria hop variety to release free odorant polyfunctional thiols in late-hopped beers
}

\author{
Cécile Chenot $\mathbb{1}^{\circ}$ and Sonia Collin*
}

\begin{abstract}
The cysteinylated and glutathionylated precursors of 3-sulfanylpentanol (Cys-3SPol up to $197 \mu \mathrm{g} / \mathrm{kg}, \mathrm{G}-3 \mathrm{SPol}$ up to $14 \mathrm{mg} / \mathrm{kg}$ ), recently reported in hops, were quantitated for the first time in the Mandarina Bavaria variety, along with the ubiquitous cysteinylated and glutathionylated forms of 3-sulfanylhexanol (Cys-3SHol up to $897 \mu \mathrm{g} / \mathrm{kg}, \mathrm{G}-3 \mathrm{SHol} \mathrm{up}$ to $46 \mathrm{mg} / \mathrm{kg}$ ). In contrast to findings with another new German cultivar, Polaris, no trace of 3-sulfanyl-4-methylpentanol adducts (Cys- and G3S4MPol) was found. To assess the transfer rate of thiols from hops to finished beer, the same pilot Mandarina Bavaria hopped wort was fermented with two different dry yeasts, bottle refermented or not, and analysed. The data were compared with results obtained for a similarly produced commercial beer. In conclusion, despite significant variation between harvest years, Mandarina Bavaria appears not to contain outstanding amounts of free thiols or thiol S-conjugates. Its S-conjugate pool is sufficient, however, to bring $3 \mathrm{SHol}$ above its odour threshold. This work also suggests that since 354MPol was found near or above its threshold in most late-hopped beers it does not originate from hops and that malt may be its main contributor. $\odot 2021$ The Institute of Brewing \& Distilling
\end{abstract}

Keywords: Mandarina Bavaria; hops; polyfunctional thiols; late-hopped beers

\section{Introduction}

Hop (Humulus lupulus L.) made its first appearance in the brewing process at the end of the $8^{\text {th }}$ century $A D(1)$, its main purpose being to prevent beer spoilage through the bacteriostatic effect against Gram+ bacteria (2). It quickly became one of the main ingredients imparting bitterness and flavour. For a long time, hops were classified as either being high bitterness or aromatic, on the basis of their $\alpha$-acid content ( $>$ or $<7 \%$, respectively). Yet over the past few decades, new dual purpose varieties have been produced, characterised by hop cones rich in both $\alpha$-acids and essential oils. These dual purpose hops are a direct response to the growing demand of brewers, especially craft brewers, for varieties that can increase the possibility of late hopping and new dry hopping processes (3).

US hop growers were the first to respond to this increasing demand for dual hops. Since the early 2000's, they have been providing hop varieties with strong differentiating aroma notes, such as Centennial, Chinook, Citra, and Amarillo. In 2018, 59\% of the worldwide hop acreage was used to produce these flavour hops.

Noble and high alpha varieties with traditional hoppy characteristics have monopolised German hop breeding for decades (4). In 2006, to pave the way of German hops for use by craft brewers, a new breeding programme was launched at the Hop Research Centre Huell. Its objective was to develop hops combining distinctive fruity, citrusy, floral, and exotic aroma impressions, more characteristic of US flavour hops, with the progeny disease resistance, agronomic performances, and traditional herbal, wood, and spicy notes typical of European cultivars. For this, crosses were made between the US Cascade and male Huell. From all the hop breeding lines and brewing trials, a few varieties have been selected and registered. Among them, Mandarina Bavaria (7-10\% w/w $\alpha$-acids; 1.5-2.2 $\mathrm{ml} / 100 \mathrm{~g}$ total oils/dried cones) is described as fruity with pronounced mandarin and citrus notes combined with traditional hoppy nuances. This aromatic profile, with its similarities to those of Cascade and Centennial US hops, is unique in the Huell hop portfolio $(4,5)$. Since its commercialisation, Mandarina Bavaria has already been widely used for late and dry hopping applications. The resulting beers appear to be appreciated, with excellent drinkability, a pronounced mandarin orange aroma, and high fruity citrusy potential $(4,6)$.

To determine the varietal contributors of this unique aroma and flavour impression to beers, there have been a number of studies of the essential oil composition of Mandarina Bavaria hop. The later the harvest, the higher the total oil content (7). With 140 $\mathrm{mg} / \mathrm{kg}$, geraniol is quite prominent in this variety. A comparison of all the new dual German varieties has revealed linalool, known as a hop derived key aroma compound in hoppy beers $(8,9)$, as playing the least variety dependent role (6). In late-hopped beers, however, linalool can achieve concentrations (42.1 $\mu \mathrm{g} / \mathrm{L})$ above its odour threshold (5-44 $\mu \mathrm{g} / \mathrm{L})(10)$, while geraniol usually remains below one flavour unit (11). Beer terpenols can arise not only through direct transfer of the free form from hop, but also through release from precursors in which they are glycosidically bound or through yeast biotransformation (12). For example, geraniol can be metabolised to linalool or $\beta$-citronellol, especially after late hopping (13). On the other hand and whatever the cultivar, delaying

\footnotetext{
* Correspondence: Sonia Collin, Unité de Brasserie et des Industries Alimentaires, LIBST Institute, Faculté des Bioingénieurs, Université Catholique de Louvain. Croix du Sud, 2 box L7.05.07, B-1348 Louvain-la-Neuve, Belgium. Email: sonia.collin@uclouvain.be
}

Unité de Brasserie et des Industries Alimentaires, LIBST Institute, Faculté des Bioingénieurs, Université Catholique de Louvain, Croix du Sud, 2 box L7.05.07, Louvain-la-Neuve B-1348, Belgium 
hop addition makes it possible to avoid geraniol consumption during the yeast growth phase (11).

Regarding polyfunctional thiols, levels of 4-sulfanyl-4methylpentan-2-one (4S4M2Pone) and 3-sulfanylhexan-1-ol (3SHol) are very low in Mandarina Bavaria (1.1 and $5.7 \mu \mathrm{g} / \mathrm{kg}$, respectively) compared to American, New Zealand and Australian dual hops (up to 36.6 in Citra and $23.2 \mu \mathrm{g} / \mathrm{kg}$ in Ekuanot, respectively) (14). Yet in the late-hopped beers, $3 \mathrm{SHol}$ can be found at concentrations well above its threshold (10 times as high as expected, considering the hopping rate and free thiol content), suggesting the occurrence of glutathionylated (G-) or cysteinylated (Cys-) precursors. Roland et al (15) have confirmed this by identifying and quantifying for the first time $\mathrm{S}$-conjugates forms of 4S4M2Pone and $3 \mathrm{SHol}$ in Mandarina Bavaria (20 $\mu \mathrm{g} / \mathrm{kg}$ of Cys-4S4M2Pone, G-4S4M2Pone not detected, 129 and $2119 \mu \mathrm{g} / \mathrm{kg}$ of Cys- and G-3SHol, respectively). This is not the case of 3-sulfanyl-4-methyl-pentan-1-ol (3S4MPol), whose level in beer was proposed to be strictly determined by the hop free content (14). In malt, only the S-conjugates of 3SHol have been found so far (16).

The aim of this paper was to complete the reported thiol adduct profile of Mandarina Bavaria hop using two complementary HPLC-MS methods recently applied to Polaris (17), another German dual hop. These analyses focused especially on the cysteinylated and glutathionylated adducts of three sulfanylalkyl alcohols, recently reported in other dual hop varieties (structures and abbreviations detailed in Figure 1). Pilot beers late hopped with Mandarina Bavaria were further analysed by GC-PFPD after selective $\mathrm{pHMB}$ extraction, in order to assess the release of free thiols from cysteinylated and glutathionylated adducts through boiling and fermentation. One commercial Mandarina Bavaria late-hopped beer was also investigated.

\section{Materials and methods}

\section{Hop samples}

Two Mandarina Bavaria hop samples (2017 and 2019 harvest, 7.1 and $8.1 \%$ alpha acids, respectively) were kindly provided by Hopsteiner (Germany) for S-conjugates analyses. The former was used to produce pilot beer samples, the later for the commercial beer.

\section{Pilot-scale production of Mandarina Bavaria late-hopped beers}

Beers were produced in a $60 \mathrm{~L}$ microbrewery (Coenco, Belgium) as described previously (18). In the brewing process, $13.65 \mathrm{~kg}$ of malt, $12.75 \mathrm{~kg}$ of Heineken type pale malt (Boortmalt, Belgium) and 0.9 $\mathrm{kg}$ of Cara 50 malt (Goldswean, Belgium) were brewed with 37.6 $\mathrm{L}$ of brewing water according to the following mashing program: $60 \mathrm{~min}$ at $63^{\circ} \mathrm{C}$ and $20 \mathrm{~min}$ at $73^{\circ} \mathrm{C}$. The wort was then heated to $78^{\circ} \mathrm{C}$ and filtered through the lauter tun at a $0.8 \mathrm{~L} / \mathrm{min}$ flow. The $13^{\circ}$ Plato (60L) wort obtained was boiled with $0.58 \mathrm{~g} / \mathrm{L}$ of Mandarina Bavaria pellets for 90 min (10\% evaporation). Just before the whirlpool, Mandarina Bavaria pellets were added at 2 $\mathrm{g} / \mathrm{L}$. The remaining cold clarified wort was divided into two and fermented in cylindroconical fermentation tanks pitched with dry top fermented yeast at $0.5 \mathrm{~g} / \mathrm{L}$, one with BE-134 Fermentis yeast strain (BE-134 and BE-134* samples) and one with BE-256 Fermentis yeast strain (BE-256* sample). The fermentation was at $20^{\circ} \mathrm{C}$ for 7 days, followed by maturation for 3 days at $4^{\circ} \mathrm{C}$. After filtration on plates $(0.5 \mu \mathrm{M}$ pores, Buon Vino, Cambridge, Canada), BE-134 sample was stored under carbon dioxide until extraction, while for samples BE-134* and BE-256*, bottle refermentation

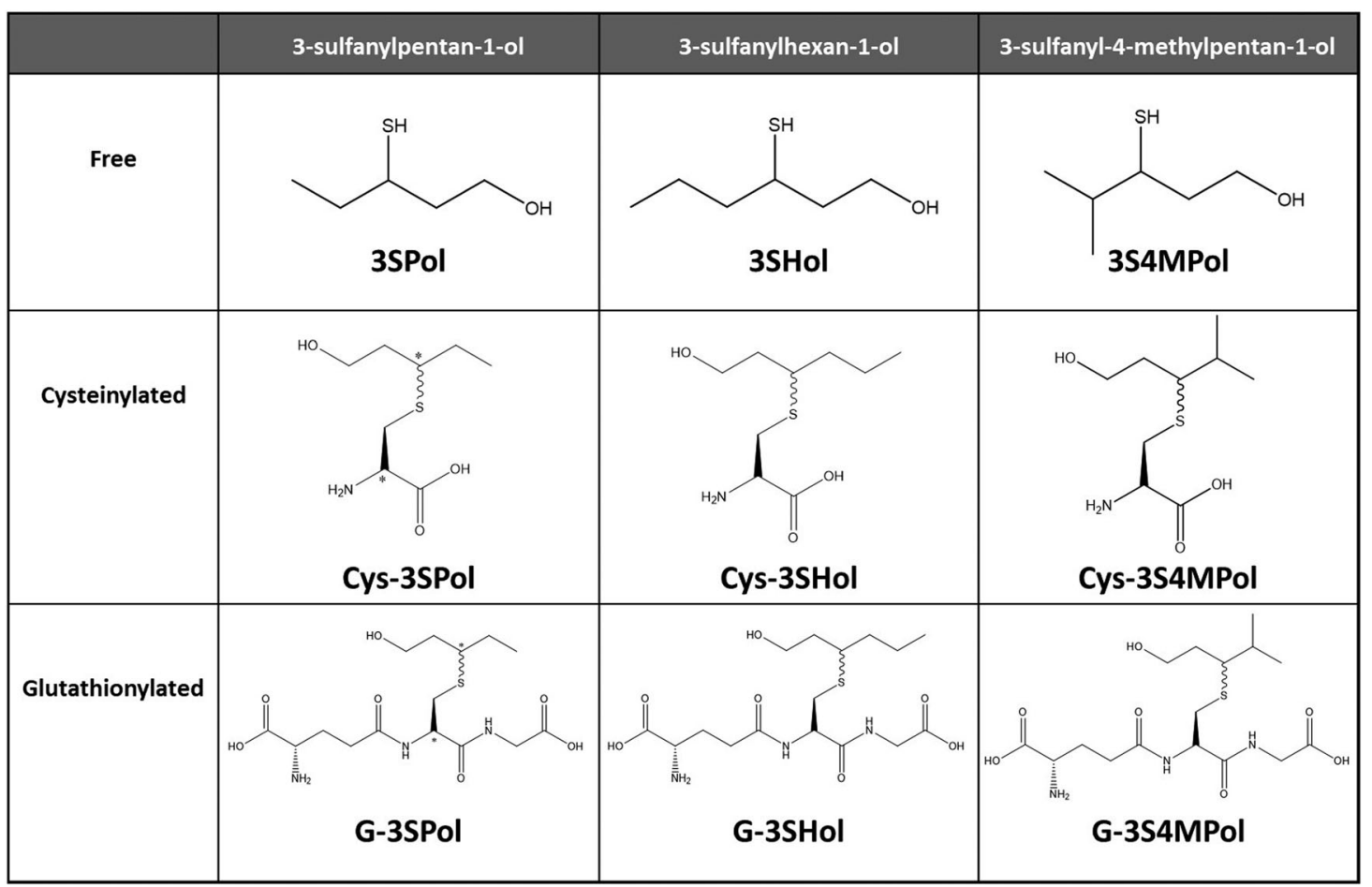

Figure 1. Chemical structures of three odorant sulfanylalkyl alcohols and their corresponding precursors. 
was applied (with BE-256 Fermentis yeast strain pitched at 100,000 cells $/ \mathrm{mL} /{ }^{\circ}$ alcohol and the addition of $12 \mathrm{~g} / \mathrm{L}$ of sucrose). The * symbol is used throughout the text to indicate which samples were bottle refermented.

\section{Commercial Mandarina Bavaria late-hopped beers}

The refermented commercial bottled beer was selected for its recipe which was very similar to the pilot scale production. The beer contained a small percentage of $50{ }^{\circ} \mathrm{EBC}$ special malt, was latehopped with $2 \mathrm{~g} / \mathrm{L}$ Mandarina Bavaria, and BE-256 Fermentis yeast strain was used for pitching.

\section{Chemicals}

Absolute ethanol, Amberlite IR-120 resin, 28\% ammonia, dichloromethane, formic acid, and $37 \%$ hydrochloric acid were purchased from VWR (Leuven, Belgium). 2-Acetylthiophene, apotryptophanase, Dowex resin 1x2 chloride form, 4-(hydroxymercuri) benzoic acid sodium salt $(p \mathrm{HMB}),>98 \% \mathrm{~L}-$ cysteine hydrochloride monohydrate, 4-methoxy-2methylbutane-2-thiol, S-benzyl-L-cysteine and S-hexylglutathione were purchased from Sigma-Aldrich (Bornem, Belgium). Sodium hydroxide was purchased from Acros Organics (Geel, Belgium). Pyridoxal 5-phosphate was purchased from Alfa Aesar (Haverhill, Massachusetts, USA). Ethylenediaminetetraacetic acid was purchased from JT Baker Chemicals (Radnor Township, Pennsylvania, USA). di-Potassium hydrogen phosphate was purchased from Merck (Darmstadt, Germany). Milli-Q water was used (Millipore, Bedford, MA, USA).

\section{Basic analyses of beer samples}

The Analytica EBC (19) method 9.35 was used for beer pH. Original, real, and apparent extract, density, and alcohol content (\% v/v) were determined with an Anton Paar DMA 4500M (approved by Analytica EBC).

\section{Free thiol extraction from hops and beer samples}

Polyfunctional thiols were extracted from hop pellets/beers according to the procedure (18). In the following steps: solid-liquid or liquid-liquid extraction from $15 \mathrm{~g}$ milled pellets or $750 \mathrm{~mL}$ beer with extraction of the resulting organic phase with $2 \times 30 \mathrm{~mL} p \mathrm{HMB}$ solution. Loading of the combined aqueous phase onto a strong anion-exchanger resin (preconditioned with $50 \mathrm{~mL}$ sodium hydroxide (2 M), $100 \mathrm{~mL}$ water, $50 \mathrm{~mL}$ hydrochloric acid (2 M), 100 $\mathrm{mL}$ water), rinsing impurities from the column with acetate buffer $\mathrm{pH}$ 6. Release of free thiols from $\mathrm{pHMB}$ by percolating with washed cysteine solution $(4 \times 50 \mathrm{~mL}$ dichloromethane for washing $640 \mathrm{mg}$ cysteine in $50 \mathrm{~mL}$ water), final extraction with $1 \times 10$ and $1 \times 15 \mathrm{~mL}$ bidistilled dichloromethane. Concentration to $250 \mu \mathrm{L}$ in a Danish-Kuderna distillation apparatus and to $70 \mu \mathrm{L}$ on a Dufton column. 4-Methoxy-2-methylbutane-2-thiol was added as internal standard (IST, at $67 \mu \mathrm{g} / \mathrm{kg}$ in hops and at $1.34 \mu \mathrm{g} / \mathrm{kg}$ in beer samples) and 2-acetylthiophene as external standard (EST, $1 \mathrm{~mL}$ at $200 \mu \mathrm{g} / \mathrm{L}$ added before concentration). Extraction from a beer sample is illustrated in Figure 2.

\section{Free thiol quantitation by GC-PFPD}

$p \mathrm{HMB}$ free thiol extract $(1 \mu \mathrm{L})$ was analysed with a ThermoFinnignan Trace GC 2000 gas chromatograph equipped with a splitless injector maintained at $250^{\circ} \mathrm{C}$. Compounds were

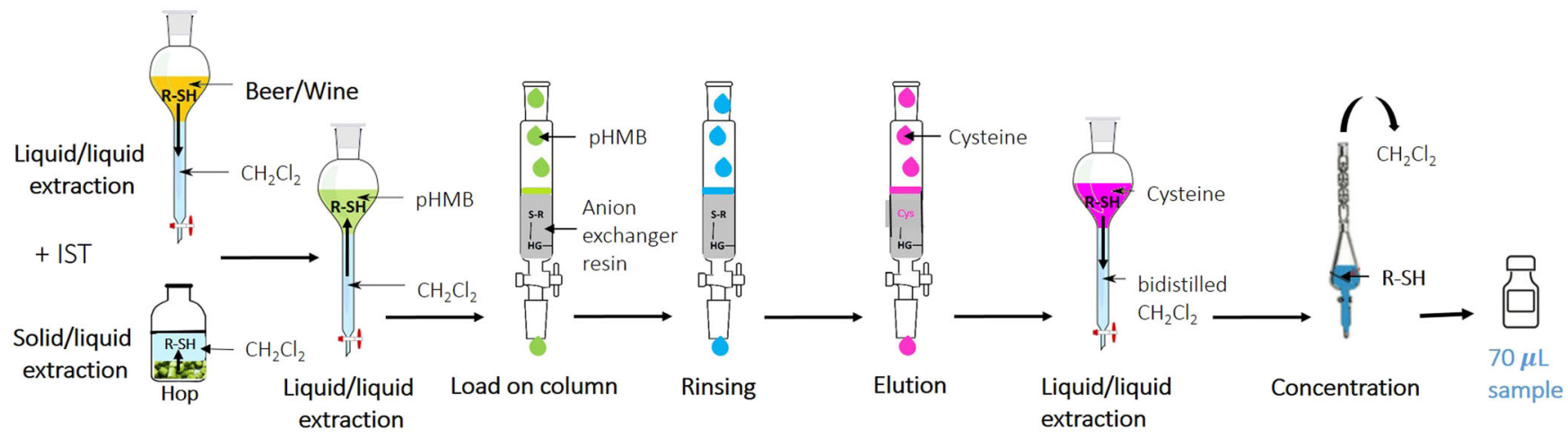

(a)
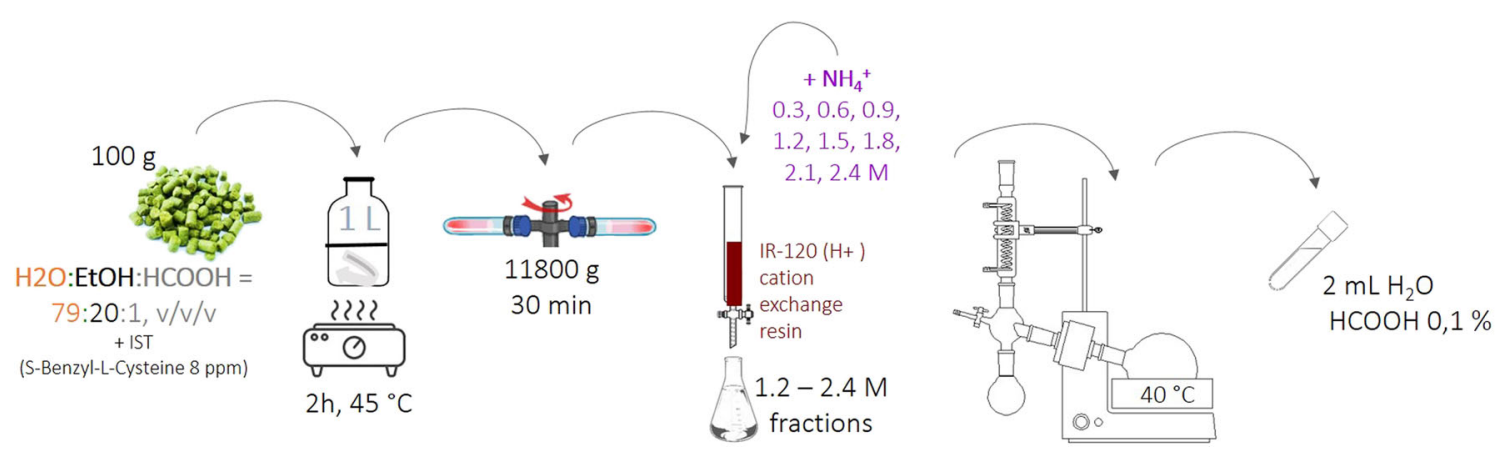

Figure 2. Sequential specific extraction of (a) free thiols (from hop or beer), (b) bound thiols (from hops). 
analysed with a wall coated open tubular (WCOT) apolar CP-Sil5CB (50 m X 0.32 mm i.d., $1.2 \mu \mathrm{m}$ film thickness) capillary column. The carrier gas was helium, and the pressure was set at $50 \mathrm{kPa}$. The oven temperature was programmed to rise from 36 to $85^{\circ} \mathrm{C}$ at $20^{\circ} \mathrm{C} / \mathrm{min}$, then to $145^{\circ} \mathrm{C}$ at $1^{\circ} \mathrm{C} / \mathrm{min}$, and finally to $220^{\circ} \mathrm{C}$ at $3^{\circ}$ $\mathrm{C} / \mathrm{min}$, and held for $30 \mathrm{~min}$. The column was connected to the $\mathrm{Ol}$ Analytical PFPD detector (model 5380, combustor internal diameter $=2 \mathrm{~mm}$ ). The following parameters were selected for the PFPD detector: temperature, $220^{\circ} \mathrm{C}$; voltage, $590 \mathrm{~V}$; gate width, $18 \mathrm{~ms}$; gate delay, $6 \mathrm{~ms}$; trigger level, $400 \mathrm{mV}$; pulse frequency, $3.33 \mathrm{~Hz}$. PFPD chromatograms were recorded throughout elution; ChemStation software was used to process the resulting data. Identification was as previously described (18). The IST-relative recovery factor was set at 1 for all compounds (experimental values from 0.8 to 1.2 , previously determined by standard addition). The good equimolarity of the PFPD detector enabled the setting the IST-relative molar response coefficients at 1.

\section{Bound thiol extraction from hop samples}

Extraction of cysteinylated and glutathionylated thiol precursors from hop pellets was performed according to (17) (Figure 2b). Milled pellets $(100 \mathrm{~g})$ were stirred with $1000 \mathrm{~mL} \mathrm{H} \mathrm{H}_{2} \mathrm{O}: \mathrm{EtOH}$ : $\mathrm{HCOOH}(79: 20: 1, v / v / v)$ for $2 \mathrm{~h}$ at $45^{\circ} \mathrm{C}$. After centrifugation, the supernatants were collected and loaded on a column of IR-120 cation exchange resin (100 g preconditioned with 100 $\mathrm{mL}$ aqueous $2 \mathrm{M} \mathrm{HCl}$ followed by $1 \mathrm{~L}$ water). The column was then washed with $800 \mathrm{~mL}$ water, and sequential $100 \mathrm{~mL}$ fractions were recovered by elution with aqueous ammonia solutions at $0.3,0.6,0.9,1.2,1.5,1.8,2.1$, and $2.4 \mathrm{~mol} / \mathrm{L}$. The 1.2 to $2.4 \mathrm{~mol} / \mathrm{L}$ fractions were pooled and concentrated under reduced pressure. The extract was either dissolved in $2 \mathrm{~mL}$ of $0.1 \%$ aqueous formic acid solution for analysis by HPLC-MS or dissolved in $2 \mathrm{~mL}$ of potassium phosphate buffered solution for enzymatic assay.

\section{Bound thiol quantitation by High Performance Liquid Chromatography - Mass Spectrometry (HPLC-MRM)}

The previously synthesised $(17,20,21)$ cysteinylated and glutathionylated precursors of $3 \mathrm{SPol}, 3 \mathrm{SHol}$, and $354 \mathrm{MPol}$ were used for identification and quantitation. The two complementary columns - strategy described by (17) - was applied to identify and quantify these molecules in hop samples.

A $100 \mathrm{~mm} \times 2.1 \mathrm{~mm}, 3 \mu \mathrm{m}$ Hypersil GOLD ${ }^{\mathrm{TM}}$ aQ column (a polar endcapped $\mathrm{C} 18$ phase offering superior retention of polar compounds, ThermoFisher) was first used to quantify Cys-3SPol, Cys3SHol+Cys-3S4MPol, and G-3SPol. A $250 \mathrm{~mm} \times 4.6 \mathrm{~mm}, 5 \mu \mathrm{m}$ Astec $^{\circledast}$ Cyclobond $^{\circledast}$ । 2000 RSP (chiral column used here for its polarity and not for its chirality, Sigma Aldrich) was then used to quantify G-3SHol and G-3S4MPol distinctively.

For both columns, the elution solvents were acidified $(0.1 \%$ formic acid) water (solvent A) and acetonitrile (solvent B) $(0.005 \%$ formic acid in water with the Cyclobond to remain above $\mathrm{pH} 4$, within the $\mathrm{pH}$ stability range of the column). When using the Hypersil GOLD ${ }^{\mathrm{TM}} \mathrm{aQ}$ column, the gradient elution was as follows: $100 \%$ of solvent $A$ for $10 \mathrm{~min}$, from 100 to $98.6 \%$ in $15 \mathrm{~min}$, maintained for $5 \mathrm{~min}$, from 98.6 to $85 \%$ in $20 \mathrm{~min}$, decrease to $10 \%$ in $1 \mathrm{~min}, 10 \mathrm{~min}$ of washing, and back to the original conditions in $5 \mathrm{~min}$ for $15 \mathrm{~min}$. The flow rate was set at $350 \mu \mathrm{L} / \mathrm{min}$. Ten microliters of sample were injected onto the column at $50{ }^{\circ} \mathrm{C}$. As for Astec $^{\circledast}$ Cyclobond $^{\oplus}$ । 2000 RSP column, the gradient elution was as follows: for solvent $A$, $95 \%$ for $5 \mathrm{~min}$, from 95 to $50 \%$ in $5 \mathrm{~min}$, 50\% maintained for $25 \mathrm{~min}$, from 50 to $10 \%$ in $1 \mathrm{~min}, 10 \%$ maintained for $9 \mathrm{~min}$, then back to the original conditions in $3 \mathrm{~min}$ for $12 \mathrm{~min}$. The flow rate was set at $800 \mu \mathrm{L} / \mathrm{min}$. Sample $(10 \mu \mathrm{L})$ was injected onto the column at room temperature. A system equipped with an autosampler and a quaternary pump (Agilent Technologies, 1200 series) was used. The system was controlled with Agilent Chem Station software. Mass spectra were acquired with a Bruker Daltonics Esquire 3000 ion trap mass spectrometer equipped with an electrospray ion source (Bruker) operated in positive mode $(E S I+)$. The ESI inlet conditions were as follows: source voltage $4.5 \mathrm{kV}$; capillary temperature $365^{\circ} \mathrm{C}$; nebulizer pressure and flow rate of the drying gas (nitrogen) 40 Psi and $8 \mathrm{~mL} / \mathrm{min}$. To provide optimised detection and quantitation of each kind of precursors, the MS was tuned with two commercially available cysteine and glutathione conjugates (S-benzylcysteine, also used as internal standard and S-hexyl-glutathione). For identification by Tandem Mass Spectroscopy (MS/MS), collision-induced dissociation spectra were recorded at a relative collision energy of $0.5 \mathrm{~V}$. The following $\mathrm{m} / \mathrm{z}$ were screened: $\mathrm{m} / \mathrm{z}$ 208 for Cys-3SPol, m/z 222 for Cys-3SHol and Cys-3S4MPol, m/z 394 for G-3SPol, m/z 408 for G-3SHol and G-3S4MPol. For quantitation, the Multiple Reaction Monitoring (MRM) mode, consisting in quantifying only a selected ion issued from the fragmentation reaction of the molecular ion in the second mass spectrometer stage (22), was applied. A relative collision energy of $0.8 \mathrm{~V}$ was used to maximise the fragmentation of the molecular ion and the major fragment for each compound was selected: $m / z 208 \rightarrow 191$ for Cys-3SPol, $m / z \quad 394 \rightarrow 248$ for G-3SPol, $m / z 222 \rightarrow 205$ for Cys-3SHol and Cys-3S4MPol, $m / z$ $408 \rightarrow 262$ for G-3SHol and G-3S4MPol.

Calibration curves of adducts relative to IST were determined for all synthetic standards and the following equation was used for each adduct quantitation: concentration of adduct (in $\mu \mathrm{g} / \mathrm{kg}$ ) = concentration of IST (in $\mu \mathrm{g} / \mathrm{kg}) \times($ peak area of adduct/peak area of IST) $\times$ (response coefficient of IST/response coefficient of adduct).

The following equation was used to express adduct concentrations in free thiol equivalents: concentration of free thiol equivalent (in $\mu \mathrm{g} / \mathrm{kg}$ ) = concentration of adduct (in $\mu \mathrm{g} / \mathrm{kg}) \times$ (molecular weight of thiol/molecular weight of the corresponding adduct).

\section{Distinctive cysteine adducts quantitation by enzymatic assay and GC-PFPD}

To establish the Cys-3SHol/Cys-3S4MPol ratio from the Cys-3SHol +Cys-3S4MPol amount obtained by HPLC-MRM, an enzymatic treatment (20) was applied to hop precursors extracts. After dissolution in $2 \mathrm{~mL}$ of potassium phosphate buffered solution $(100 \mathrm{mM}$, $\mathrm{pH}$ 7.7) containing pyridoxal 5-phosphate $(0.1 \mathrm{mM})$ and ethylenediaminetetraacetic acid $(1 \mathrm{mM})$, the extract was mixed with 0.5 $\mathrm{mL}$ of a solution containing the commercial apotryptophanase from Escherichia coli (75-150 units/mg) freshly prepared (1 mg in $0.5 \mathrm{~mL}$ of buffer). The mixture was kept at $28^{\circ} \mathrm{C}$ for $30 \mathrm{~min}$ and then stirred with $5 \mathrm{~mL}$ of bi-distilled dichloromethane for $30 \mathrm{~min}$. A control without enzyme was conducted in parallel. The organic phase was recovered, dried over sodium sulphate and concentrated to $500 \mu \mathrm{L}$ in a Danish-Kuderna and to $70 \mu \mathrm{L}$ in a Dufton column. 1 $\mu \mathrm{L}$ of the obtained extract was analysed by GC-PFPD. 

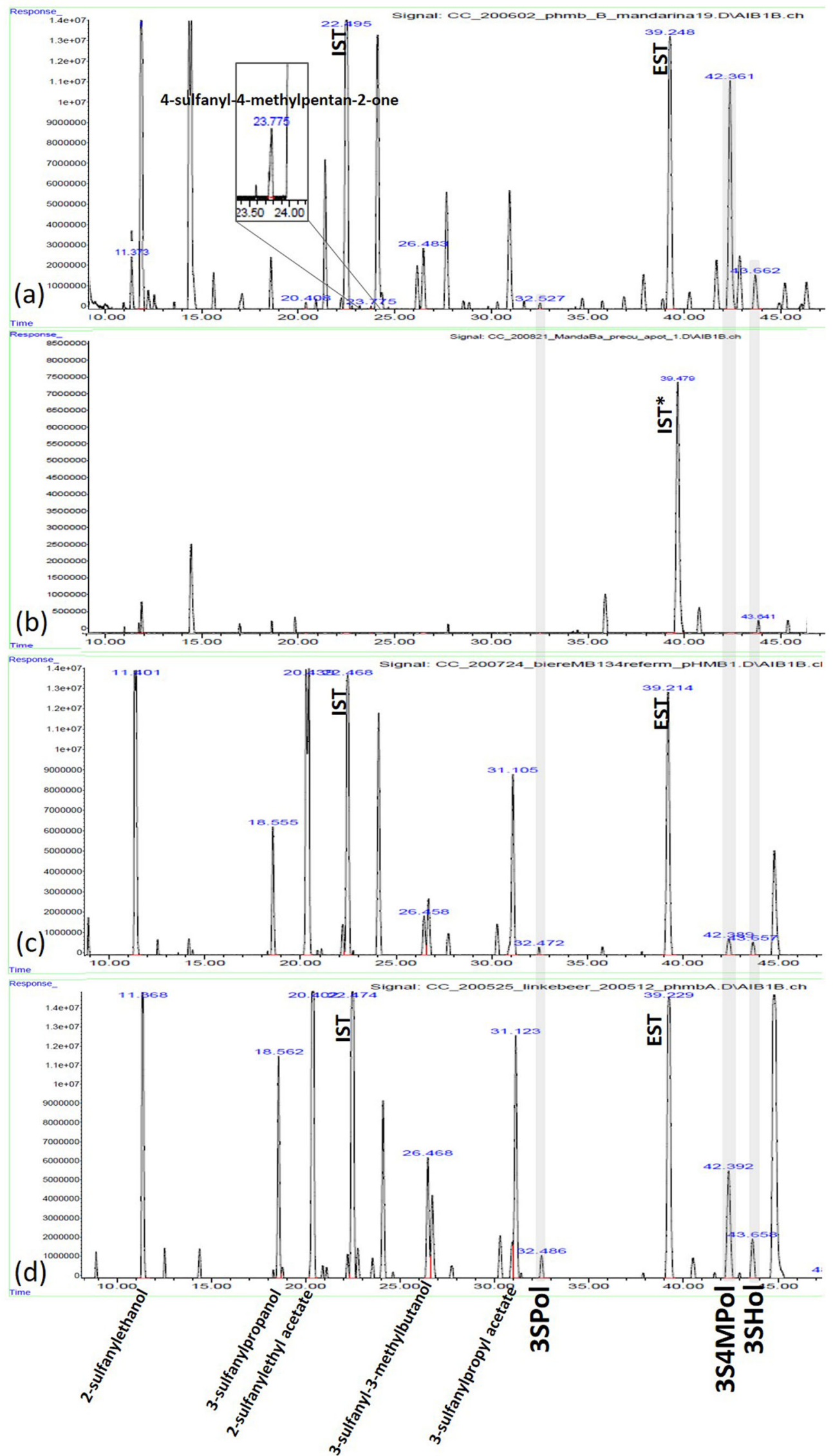

Figure 3. GC-PFPD chromatograms of pHMB extracts issued from (a) Mandarina Bavaria hop (2019 crop year), (b) Mandarina Bavaria hop (2019 crop year) after apotryptophanase incubation (IST* ${ }^{*}$ benzylthiol released from S-benzyl-L-cysteine), (c) BE-134* pilot beer sample and (d) commercial Beer*. 


\section{Results and discussion}

\section{Free sulfanylalkyl alcohols in Mandarina Bavaria hop}

The GC-PFPD chromatogram obtained after selective pHMB extraction of free polyfunctional thiols is presented for the 2019 harvest in Figure 3a. Table 1 details the concentrations of 3SPol, 3SHol, and 3S4MPol in both harvests (2017 and 2019). Compared to other dual varieties such as Tomahawk, Nelson Sauvin, Cascade, Citra, Ekuanot, and Hallertau Blanc (14, 18), Mandarina Bavaria was not rich in free thiols $(0.4-6.1 \mu \mathrm{g} / \mathrm{kg} 3 \mathrm{SHol}$ vs $117 \mu \mathrm{g} / \mathrm{kg}$ in Cascade, nd. $-0.5 \mu \mathrm{g} / \mathrm{kg} 3 S$ Pol vs $10 \mu \mathrm{g} / \mathrm{kg}$ in Amarillo, nd. - $0.3 \mu \mathrm{g} / \mathrm{kg}$ 4S4M2Pone vs $37 \mu \mathrm{g} / \mathrm{kg}$ in Citra (14), 1.8-6.6 $\mu \mathrm{g} / \mathrm{kg}$ 3-sulfanyl-3methylbutan-1-ol vs $36 \mu \mathrm{g} / \mathrm{kg}$ in Nelson Sauvin (14)).

Significant differences were found, however, between the two harvests. As for other plants, climate during growth or date of harvesting probably affect the abiotic or biotic stresses linked to the occurrence of thiols. In 2019, the rhubarb/grapefruit-like 3S4MPol reached $29.1 \mu \mathrm{g} / \mathrm{kg}$, a level above those usually found in Cascade $(6 \mu \mathrm{g} / \mathrm{kg})$ and Galaxy $(26 \mu \mathrm{g} / \mathrm{kg})$ hops. Only Ekuanot, Hallertau Blanc, and Nelson Sauvin appear even richer (282, 295, and $305 \mu \mathrm{g} / \mathrm{kg}$, respectively) (14). The sample from harvest 2019 was more consistent with published values ( 5.7 and $61 \mu \mathrm{g} / \mathrm{kg}$ for $3 \mathrm{SHol}$ and $3 \mathrm{~S} 4 \mathrm{MPol}$, as reported previously (14)). If only free forms were available and considering a $100 \%$ recovery rate from hop to beer, the richer harvest (2019) would have to be added at $0.24 \mathrm{~kg} / \mathrm{hL}$ to reach the sensory threshold of $354 \mathrm{MPol}$ (70 $\mathrm{ng} / \mathrm{L}$ in beer).

\section{Bound thiols in Mandarina Bavaria hop}

For quantification of precursors, a strategy using two HPLC columns was applied as previously described for analysis of Polaris (17). With the first column (Hypersil GOLD ${ }^{\mathrm{TM}} \mathrm{aQ}$ column), both cysteine and glutathione adduct can be quantitated (Figure 4a, two peaks not always completely resolved for each adduct, because of diastereoisomers). Unfortunately, as this column does not distinguish $3 \mathrm{SHol}$ precursors from $354 \mathrm{MPol}$ precursors (same retention time and $\mathrm{m} / \mathrm{z}$, positional isomers), the more polar Astec ${ }^{\circledast}$ Cyclobond $^{\oplus}$ I 2000 RSP column is preferred to quantitate G-3SHol and G-3S4MPol distinctively (Figure 4b). For quantitation of Cys-3SHol and Cys-3S4MPol, the enzymatic assay using apotryptophanase was applied (Figure 3b) (20).

As reported for all previously studied varieties, glutathione adducts emerged with the biggest aroma potential (for $3 \mathrm{SHol}$, $10^{6}$ times as much adduct as free form). Also noteworthy is that the G-3SHol content reached 3 to 6 times the G-3SPol content (17). As recently reported for Polaris, trans-2-hexenal (precursor of $\mathrm{G}-3 \mathrm{SHol}$ ) is from the major oxidation pathway of linolenic acid, while G-3SPol requires the involvement of minor routes (17). Both the Astec $^{\circledast}$ Cyclobond $^{\circledast}$ I 2000 RSP HPLC column and the apotryptophanase enzymatic assay revealed the total absence of 3S4MPol adducts (Cys- and G-3S4MPol) in Mandarina Bavaria, despite the presence of $8.7 \mu \mathrm{g} / \mathrm{kg}$ free form.

\section{Free polyfunctional thiols transferred to beer by late hopping}

To highlight the organoleptic impact of late hopping with Mandarina Bavaria, polyfunctional thiols were quantified in three pilot beers (BE-134, BE-134*, BE-256*) after pHMB extraction. One commercial refermented Belgian bottled beer (Beer*) produced in a similar way was also investigated. As expected, both the yeast strain and the bottle refermentation process strongly influenced the real extract and alcohol content (Table 2). S. diastaticus strain $\mathrm{BE}-134$ was more attenuating, resulting in $3.8^{\circ} \mathrm{P}$ and $6.2 \% \mathrm{ABV}$. Bottle refermentation (BE-134*) pushed further the attenuation to $3.2^{\circ} \mathrm{P}$ real extract and $7.1 \% \mathrm{ABV}$.

Free polyfunctional thiols were extracted from pilot and commercial beer samples with the $\mathrm{pHMB}$ procedure and analysed with the PFPD specific detector (Figures 3c, 3d and Table 3).

Among the major polyfunctional thiols found in beer samples (Table 3), 2-sulfanylethan-1-ol (2SEol), 2-sulfanylethyl acetate (2SEA), 3-sulfanylpronan-1-ol (3SProl), and 3-sulfanylpropyl acetate (3SPrA) are known to be associated with the yeast Ehrlich pathway

Table 1. Free and bound forms of three sulfanylalkyl alcohols in Mandarina Bavaria hop, compared to the maximum values reported in literature for other varieties. All contents are given in free form equivalents (true values in parentheses)

\begin{tabular}{|c|c|c|c|c|c|c|c|c|c|}
\hline & \multicolumn{3}{|c|}{ Free form $(\mu \mathrm{g} / \mathbf{k g})$} & \multicolumn{3}{|c|}{ Cysteinylated form ( $\mu \mathrm{g} / \mathbf{k g})$} & \multicolumn{3}{|c|}{ Glutathionylated form (mg/kg) } \\
\hline & \multicolumn{2}{|c|}{$\begin{array}{c}\text { Mandarina } \\
\text { Bavaria }^{a}\end{array}$} & \multirow{2}{*}{$\begin{array}{l}\text { Maximum found } \\
\text { in another variety } \\
\text { - } \quad(3,14,18)\end{array}$} & \multicolumn{2}{|c|}{ Mandarina Bavaria ${ }^{\mathbf{b}}$} & \multirow{2}{*}{$\begin{array}{c}\text { Maximum } \\
\text { found in } \\
\text { another } \\
\text { variety }(15,17)\end{array}$} & \multicolumn{2}{|c|}{ Mandarina Bavaria ${ }^{\mathbf{b}}$} & \multirow{2}{*}{$\begin{array}{c}\begin{array}{c}\text { Maximum } \\
\text { found in } \\
\text { another }\end{array} \\
\text { variety }(15,17\end{array}$} \\
\hline & 2017 & 2019 & & 2017 & 2019 & & 2017 & 2019 & \\
\hline 3SPol & nd. & 0.5 & $\begin{array}{c}10.0 \\
\text { (Amarillo) }\end{array}$ & d. & $114(197)$ & $\begin{array}{l}93 \text { (161) } \\
\text { (Polaris) }\end{array}$ & $1.8(5.9)$ & $4.3(14.1)$ & $\begin{array}{l}5.4(18.1) \\
\text { (Citra) }\end{array}$ \\
\hline 3SHol & 0.4 & 6.1 & $\begin{array}{c}117.1 \\
\text { (Cascade) }\end{array}$ & $93^{c}(155)$ & $542^{c}(897)$ & $\begin{array}{c}2708 \text { (4484) } \\
\text { (Polaris) }\end{array}$ & $10.6(33.3)$ & $15.0(45.6)$ & $\begin{array}{c}37.8 \text { (1 18.2) } \\
\text { (Polaris) }\end{array}$ \\
\hline 3S4MPol & 8.7 & 29.1 & $\begin{array}{c}305.0 \\
\text { (Nelson Sauvin) }\end{array}$ & n.d. ${ }^{c}$ & n.d. ${ }^{c}$ & & n.d. & n.d. & $\begin{array}{l}1.1(3.6) \\
\text { (Polaris) }\end{array}$ \\
\hline \multicolumn{10}{|c|}{$\begin{array}{l}\text { a Data obtained by specific sodium 4-(hydroxymercuri)benzoate extraction of free thiols and determined by GC-PFPD ( } \mu \mathrm{g} / \mathrm{kg} \text { hop, IST } \\
\text { equivalents). nd, undetected. } \\
{ }^{b} \text { Data obtained by S-conjugate-specific extraction and determined by HPLC-MS/MS ( } \mathrm{mg} / \mathrm{kg} \text { hops, calibration curves relative to IST). d, } \\
\text { detected at trace level }(<50 \mu \mathrm{g} / \mathrm{Kg} \text { ). nd, undetected. i. identified but not quantified. /, no data. 'Distinctive data obtained using the } \\
\text { indirect method with apotryptophanase enzymatic assay. }\end{array}$} \\
\hline
\end{tabular}


$(25,26)$. On the basis of their sensory thresholds, these Ehrlich derived thiols should not significantly affect the perceived flavour in any sample. Surprisingly, in contrast to other beers, all samples contained lower amounts of 3SProl than of its ester 3SPrA (3SProl/3SPrA ratios of $0.58,0.36,0.34$, and 0.44 for BE-134, BE$134^{*}$, BE-256*, and Beer*, respectively).

Among the three pilot beers, BE-134* exhibited notably higher amounts of 2SEol and its corresponding ester 2SEA (31.4 and 7.2 $\mu \mathrm{g} / \mathrm{L}$, respectively vs about 20 and $2.5 \mu \mathrm{g} / \mathrm{L}$ ). Compared to BE134 , the additional bottle refermentation significantly increased the amount of both Ehrlich compounds issued from cysteine. BE$256^{*}$, on the other hand, exhibited the highest amount of 3SProl and its corresponding ester 3SPrA ( 1.1 and $3.4 \mu \mathrm{g} / \mathrm{L}$ respectively vs about 0.4 and $0.9 \mu \mathrm{g} / \mathrm{L}$ ), both issued from homocysteine. These results suggest that $\mathrm{BE}-256$ yeast could be better at metabolising homocysteine than BE-134.

All the varietal sulfanylalkyl alcohols found in Mandarina Bavaria hop were detected in beer samples (except 3SPol in BE-134). Because of the presence of bound forms in hops, all showed levels 3 to 67 times higher than expected on the basis of hopping rate and a $100 \%$ transfer rate of free thiols from hop to beer.
The 33-50 ng/L 3SHol found in the pilot samples (close to the 55 $\mathrm{ng} / \mathrm{L}$ threshold) was 33-50 times the concentration expected for a $100 \%$ transfer rate of the free form. Yet reaching such levels should have required breakdown of only $0.02 \%$ of the $33 \mathrm{mg} / \mathrm{kg} \mathrm{G}-3 \mathrm{SHol}$ found in Mandarina Bavaria (harvest 2017). The $12 \mathrm{ng} / \mathrm{L}$ 3SPol found in $\mathrm{BE}-134^{*}$ could be explained by enzymatic or chemical release of $0.3 \%$ of its glutathione adduct. Likewise, the $113 \mathrm{ng} / \mathrm{L}$ $3 \mathrm{SHol}$ (well above its threshold) and $19 \mathrm{ng} / \mathrm{L} \mathrm{3SPol}$ found in the commercial sample could easily be derived from their S-conjugates as quantitated in hop harvest 2019.

Although felinine (Cys-3S3MBol) was not investigated in this work, it can be assumed that bound forms can also be degraded to produce up to $267 \mathrm{ng} / \mathrm{L} 3 \mathrm{~S} 3 \mathrm{MBol}$ in beer (still far below the threshold). Otherwise, hydrogen sulphide electrophilic addition on 3-methylbutenal has been shown to be a major pathway leading to the onion-like $353 \mathrm{MBol}$ in beer (27).

On the other hand, for the three pilot beers as well as the commercial sample, 3S4MPol cannot originate solely from hops (53-275 ng/L in beer, on average 4.5 times higher than the concentration expected for a $100 \%$ transfer rate of the free form). In this case neither the cysteinylated nor the glutathionylated S-conjugate have been found in hops. This constitutes the first

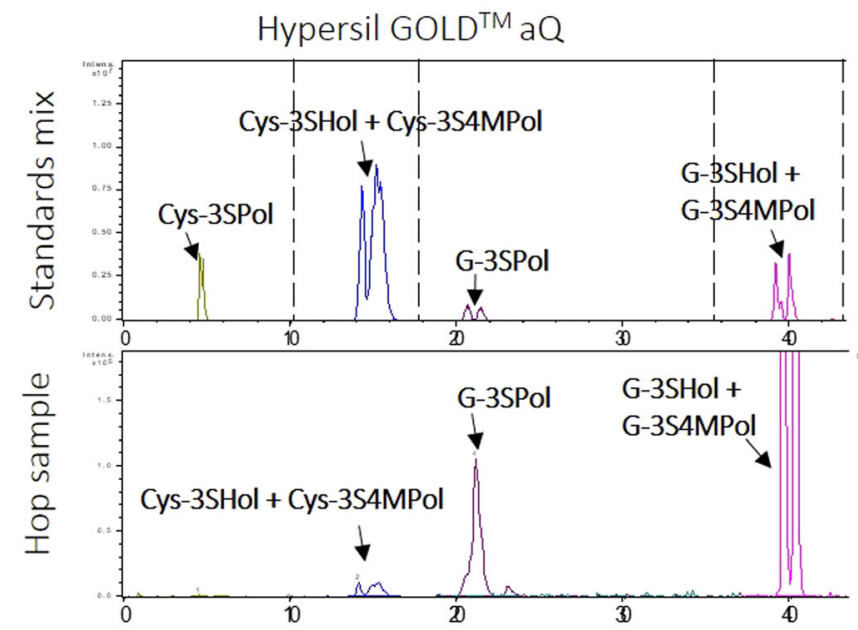

(a)

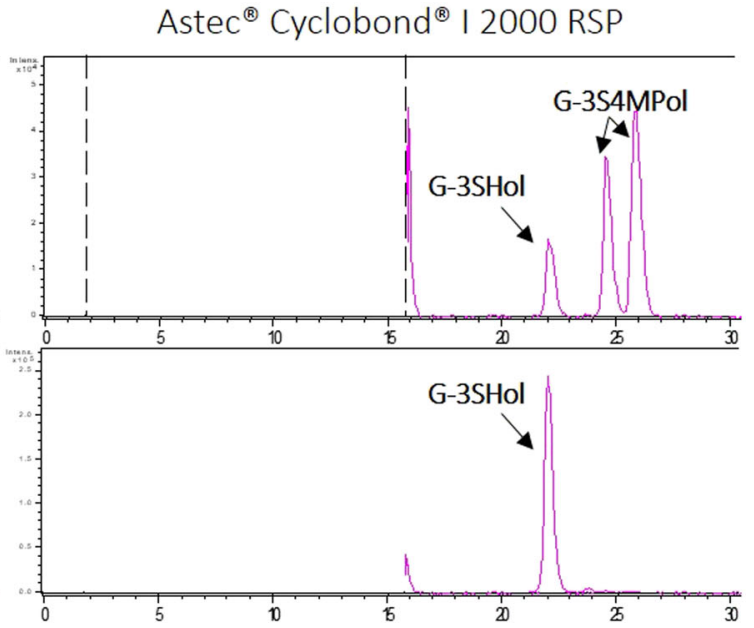

(b)

Figure 4. RP-HPLC-ESI(+)MRM (m/z $208 \rightarrow 191$ for Cys-3SPol, m/z $222 \rightarrow 205$ for Cys-3SHol and Cys-3S4MPol, m/z $394 \rightarrow 248$ for G-3SPol, m/z 408 $\rightarrow 262$ for G-3SHol and G3S4MPol) performed with (a) the Hypersil Gold aQ column and (b) the Cyclobond I 2000 RSP column, applied to a standard medium of adducts compared to the Mandarina Bavaria hop extract (2017 crop year).

Table 2. Description of the investigated pilot (BE-134, BE-134* and BE-256*) and commercial (Beer*) beers

\begin{tabular}{|c|c|c|c|c|c|}
\hline \multirow[t]{2}{*}{ Samples } & \multirow[t]{2}{*}{$\mathrm{pH}$} & \multicolumn{3}{|c|}{ Extract $\left({ }^{\circ} \mathrm{P}\right)$} & \multirow{2}{*}{$\begin{array}{l}\text { Alcoho } \\
(\% \mathrm{v} / \mathrm{v})\end{array}$} \\
\hline & & original & real & apparent & \\
\hline BE-134 & 4.2 & 13.3 & 3.8 & 1.5 & 6.2 \\
\hline BE-134* & 4.2 & 14.1 & 3.2 & 0.6 & 7.1 \\
\hline BE-256* & 4.0 & 13.9 & 5.1 & 3.0 & 5.8 \\
\hline Beer* & 4.2 & 13.7 & 5.3 & 3.3 & 5.5 \\
\hline \multicolumn{6}{|c|}{${ }^{*}$ Bottle refermented beers } \\
\hline
\end{tabular}




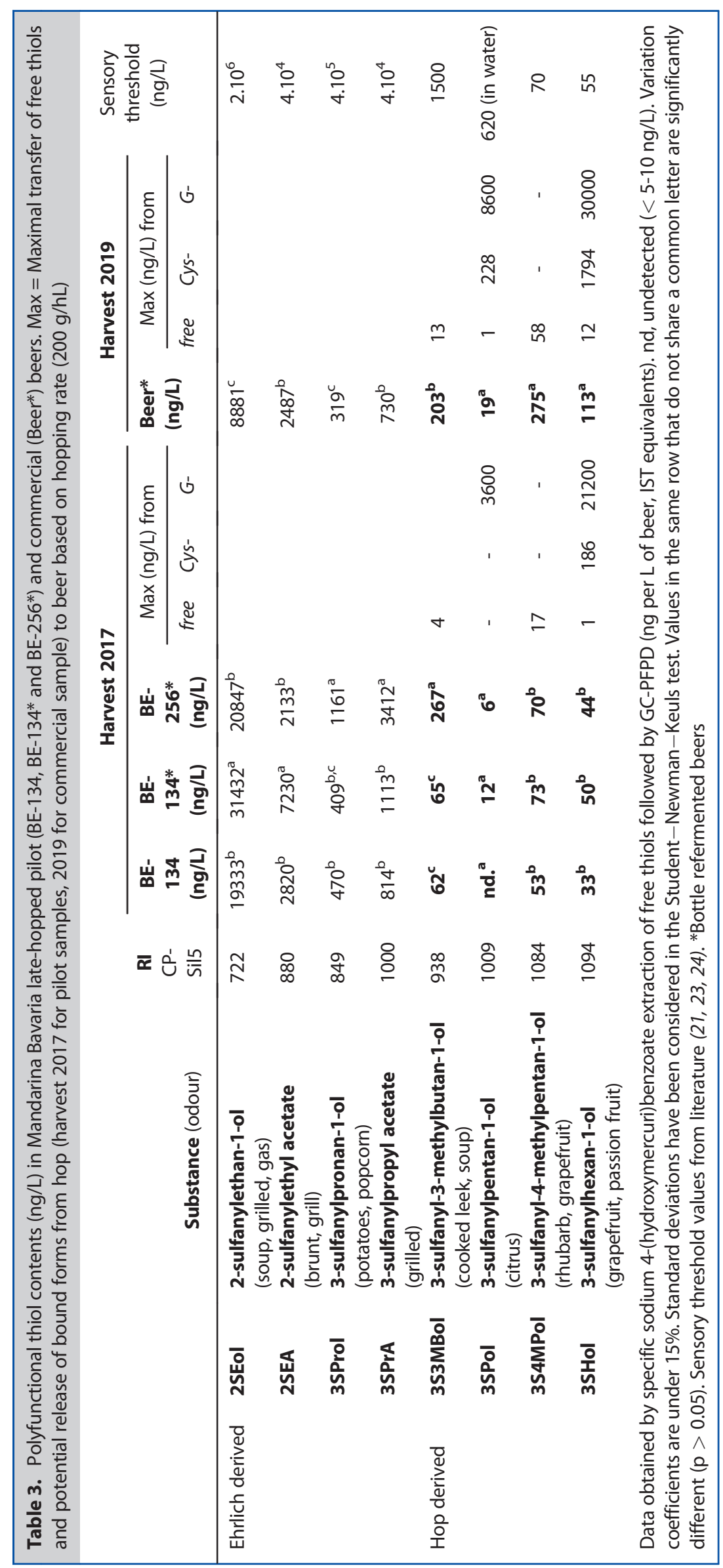


evidence that malt could be a significant contributor of 354MPol. Of course, in the case of beers dry-hopped with 3S4MPol-rich varieties, the hop contribution should remain the major contributor (up to $3.2 \mu \mathrm{g} / \mathrm{L}$ in beer dry-hopped with Mosaïc) (28).

\section{Conclusions}

This work provides, for the first time, evidence of 3SPol S-conjugates in Mandarina Bavaria, in addition to the Cys- and G$3 \mathrm{SHol}$ adducts previously investigated. Even though this variety does not contain outstanding amounts of precursors as compared to other dual or aromatic varieties, it contributes enough potential to release some appreciated volatiles, especially $3 \mathrm{SHol}$, to levels above or near their odour thresholds. The amount of 354MPol, on the other hand, raises questions. Other S-conjugate origins should now be investigated.

\section{Conflict of Interest Statement}

The authors declare there are no conflicts of interest.

\section{References}

1. Edwardson JR. 1952. Hops: their botany, history, production and utilization, Econ Bot 6:160-175.

2. Simpson WJ, and Smith AR. 1992. Factors affecting antibacterial activity of hop compounds and their derivatives. J Appl Bacteriol 72:327-334. https://doi.org/10.1111/j.1365-2672.1992.tb01843.x

3. Kankolongo M-L, Gros J, Nizet S, and Collin S. 2015. Quantitation of selected terpenoids and mercaptans in the dual-purpose hop varieties Amarillo, Citra, Hallertau Blanc, Mosaic, and Sorachi Ace. J Agric Food Chem 63:3022-3030. https://doi.org/10.1021/jf5058556

4. Lutz A, Kneidl J, Kammhuber K, and Seigner E. 2013. Breeding of special flavor hops to pave the way to the craft brewers. International Hop Growers Convention, Proceedings of the scientific commission, Kiev, Ukraine, p 21-24. https://www.lfl.bayern.de/mam/cms07/ipz/dateien/ issn_1814-2206_proceedings_kiew-2013.pdf

5. Lutz A, Kammhuber K, and Seigner E. 2012. New trend in hop breeding at the Hop Research Center Huell. Brew Sci 65:24-32.

6. Forster A, and Gahr A. 2013. On the fate of certain hop substances during dry hopping. Brew Sci 66:93-103.

7. Schnaitter $M$, Wimmer A, Kollmannsberger H, Gastl M, and Becker T. 2016. Influence of hop harvest date of the 'Mandarina Bavaria' hop variety on the sensory evaluation of dry-hopped top-fermented beer. $J$ Inst Brew 122:661-669. https://doi.org/10.1002/jib.382

8. Kaltner D, Steinhaus M, Mitter W, Biendl M, and Schieberle P. 2003. (R)-Linalool as key flavour for hop aroma in beer and its behaviour. Monatsschrift fü Brauwissenschaft 56:192-196.

9. Fritsch HT, and Schieberle P. 2005. Identification based on quantitative measurements and aroma recombination of the character impact odorants in a Bavarian Pilsner-type beer. J Agric Food Chem 53:7544-7551. https://doi.org/10.1021/jf051167k

10. Peacock VE, and Deinzer ML. 1981. Chemistry of hop aroma in beer. $J$ Am Soc Brew Chem 39:136-141.

11. Takoi K, Tokita K, Sanekata A, Usami Y, Itoga Y, Koie K, Matsumoto I, and Nakayama Y. 2016. Varietal difference of hop-derived flavour compounds in late-hopped/dry-hopped beers. Brew Sci 69:1-7.

12. Kankolongo Cibaka M-L, Silva Guimarães Ferreira $C$, Decourrière $L$, Lorenzo-Alonso C J, Bodart E, and Collin S. 2017. Dry hopping with the dual-purpose varieties Amarillo, Citra, Hallertau Blanc, Mosaic, and Sorachi Ace: minor contribution of hop terpenol glucosides to beer flavors. J Am Soc Brew Chem 2017:122.

13. Takoi K, Koie K, Itoga Y, Katayama $Y$, Shimase M, Nakayama $Y$, and Watari J. 2010. Biotransformation of hop-derived monoterpene alcohols by lager yeast and their contribution to the flavor of hopped beer. J Agric Food Chem 58:5050-5058. https://doi.org/10.1021/jf1000524

14. Takazumi K, Takoi K, Koie K, and Tuchiya Y. 2017. Quantitation method for polyfunctional thiols in hops (Humulus lupulus L.) and beer using specific extraction of thiols and gas chromatography-tandem mass spectrometry. Anal Chem 89:11598-11604. https://doi.org/10.1021/ acs.analchem.7b02996

15. Roland A, Viel C, Reillon F, Delpech S, Boivin P, Schneider R, and Dagan L. 2016. First identification and quantification of glutathionylated and cysteinylated precursors of 3-mercaptohexan-1-ol and 4-methyl-4mercaptopentan-2-one in hops (Humulus lupulus). Flavour Fragr $J$ 31:455-463. https://doi.org/10.1002/ffj.3337

16. Roland A, Delpech S, and Dagan L. 2020. Chapter 4: How to monitor positive aromatic thiols during winemaking and brewing, Hop Flavor and Aroma: Proc 2nd Int Brewers Symp, p 49-70. Shellhammer TH, Lafontaine SR (Ed), American Society of Brewing Chemists and Master Brewers Association of Americas, USA.

17. Chenot C, Robiette R, and Collin S. 2019. First evidence of the cysteine and glutathione conjugates of 3-sulfanylpentan-1-ol in hop (Humulus lupulus L.). J Agric Food Chem 67:4002-4010. https://doi.org/10.1021/ acs.jafc.9b00225

18. Gros J, Nizet S, and Collin S. 2011. Occurrence of odorant polyfunctional thiols in the super alpha Tomahawk hop cultivar. Comparison with the thiol-rich Nelson Sauvin bitter variety. J Agric Food Chem 59:8853-8865. https://doi.org/10.1021/jf201294e

19. EBC Analysis Committee. 2008. Analytica-EBC. Verlag Hans Carl, Nurnberg.

20. Gros J, Tran TTH, and Collin S. 2013. Enzymatic release of odourant polyfunctional thiols from cysteine conjugates in hop. J Inst Brew 119:221-227. https://doi.org/10.1002/jib.80

21. Kankolongo $M-L$, Decourrière L, Lorenzo-Alonso C-J, Bodart $E$, Robiette R, and Collin S. 2016. 3-Sulfanyl-4-methylpentan-1-ol in dry-hopped beers: first evidence of glutathione S-conjugates in hop (Humulus lupulus L.). J Agric Food Chem 64:8572-8582. https://doi.org/10.1021/ acs.jafc.6b03788

22. de Hoffmann E. 1996. Tandem mass spectrometry: A primer. J Mass Spectrom 31:129-137. https://doi.org/10.1002/(SICl)1096-9888 (199602)31:2<129::AID-JMS305>3.0.CO;2-T

23. Roubelakis-Angelakis KA. 2009. Grapevine Molecular Physiology \& Biotechnology. Springer Science \& Business Media.

24. Tran $T H H$, Gros J, Bailly S, Nizet S, and Collin S. 2012. Fate of 2-sulphanylethyl acetate and 3-sulphanylpropyl acetate through beer aging. J Inst Brew 118:198-204. https://doi.org/10.1002/jib.24

25. Vermeulen C, Lejeune I, Tran TTH, and Collin S. 2006. Occurrence of polyfunctional thiols in fresh lager beer. I Agric Food Chem 54:5061-5068. https://doi.org/10.1021/jf060669a

26. Gros J, Peeters F, and Collin S. 2012. Occurrence of odorant polyfunctional thiols in beers hopped with different cultivars. First evidence of an S-cysteine conjugate in hop (Humulus lupulus L.). J Agric Food Chem 60:7805-7816. https://doi.org/10.1021/jf301478m

27. Gros J, Nizet S, and Collin S. 2009. Hop allylic alcohols are precursors of sulfur-containing odorants in fresh beer. Acta Hortic 848:273-278.

28. Silva Guimarães Ferreira CA, Bodart E, Cibaka M-LK, and Collin S. 2016. What is unique in Belgian dry-hopped beers? Poster at World Brewing Congress 2016, Denver, USA. 